\title{
Most of our prescription drugs are manufactured overseas - but are they safe?
}

$\mathrm{W}$ e have to be thankful to Health Canada for helping keep the population safe from defective baby cribs, leaded paint, unpasteurized milk and a whole assortment of stuff we might ingest that could be really bad for us.

If you've seen the recent email alerts from Health Canada, you'll find that "stuff from overseas" seems to be dominating the list of things that could hurt us, best exemplified by a Jan. 25, 2012 Health Canada alert listing eight foreign products to avoid.

The list of pernicious products flowing across our borders - either being imported by travelers or bought by consumers via the Internet - includes nonprescription erectile function products (that may contain sildenafil), sold under names like Uprizing 2.0 and Ying Da Wang. ${ }^{1}$ Also on the list were 17 weight loss capsules, such as Slimina, which might contain phenolphthalein, a laxative no longer authorized for use in Canada.

While we might appreciate a government shouting buyer beware about some rather sketchy products from overseas, it forces one to ask, how much of our regular drug supply is also coming from overseas? And can we be confident it's safe?

Most Canadians probably don't know that many of our pharmaceuticals come from places like India and China. When I asked one industry insider how much of the medicines we routinely swallow everyday come from overseas, his answer was simple: most of it. Most of the North American supply of aspirin, for example, comes from China, which produces about 120 billion tablets per year. Other widely used drugs, such as omeprazole and simvastatin often come from Puerto Rico and India.

Maybe this is no big deal. But I'd like to know how often these plants are inspected. We know that manufacturing plants in Canada and the US are occasionally inspected by our government

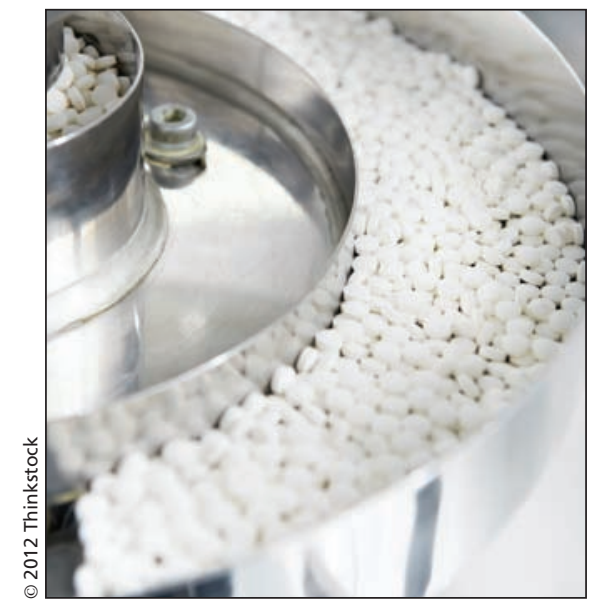

regulators, and those inspections can have consequences, like they did at the Sandoz plant in Boucherville. ${ }^{2}$ But how often do our regulators dust off their passports and fly to China or India to ensure that the plants producing pharmaceuticals are clean, follow proper manufacturing techniques and contain what is on the label (and nothing else)? In those countries where we don't have a mutual recognition agreement, we are basically trusting the integrity of the domestic inspection system. A recent scandal around heparin made in China is perhaps testimony to the kinds of serious problems that could occur if we place too much faith in the soundness of those systems.

I called Health Canada to inquire further and within seconds I was forwarded to a call centre in Mumbai. Just kidding. Actually, my call was returned by a nice woman at Health Canada who told me that we have all kinds of regulations to keep our foreign-sourced drug products safe. ${ }^{3}$

We have guidance documents. Drugs which have been manufactured, packaged/labeled, or tested at a foreign site are supposed to meet requirements set out in guidance documents. ${ }^{4}$

I was later told by email that Health Canada conducted 35 inspections at foreign sites in the last five years in what are called non-Mutual Recognition Agreement countries, those countries where we don't have standing agreements around drug manufacturing standards. They also said that "approximately $76 \%$ of drug products imported into Canada are sourced from nonMRA countries." ${ }^{4}$

How do these inspections work? What do we do when the plants fail the inspections? How often have we halted importation due to substandard drug manufacturing?

It seems we won't get these answers from Health Canada because that information is proprietary and only shared with the companies and regulatory partners (I asked).

This situation doesn't leave me with the warm fuzzies. Especially when we're dealing with - how can I say this nicely - a federal agency that refuses to even enforce the laws against illegal drug advertising on a bus shelter at the end of my street?

Am I being overly alarmed when an agency whose job it is to keep unsafe products from consumers can't even tell us which overseas manufacturers have failed inspections and why they failed?

And with recent big job cuts announced at Health Canada, I am wondering if there will be any people left to extend the vigilance they are showing toward products like Ying Da Wang to the legitimate prescription drugs we take every day.

\section{Alan Cassels MPA \\ Drug Policy Researcher \\ University of Victoria \\ Victoria, BC}

Alan Cassels is the author of Selling Sickness, and Seeking Sickness, on the medical screening industry.

For references, see Appendix 1, available at www.cmaj.ca/lookup/suppl/doi:10.1503/cmaj .120416/-/DC1.

CMAJ 2012. DOI:10.1503/cmaj.120416 